Ali Hasanpour Dehkordi $i^{*}$, Bahare Bigham², Aida Hasanpour Dehkordi', Akbar Soleimani ${ }^{*}$, Mehraban Sadeghi ${ }^{5}$

\title{
CLINICAL FEATURES, DEMOGRAPHICS, LABORATORY AND IMAGING DATA OF PATIENTS HOSPITALIZED WITH CORONAVIRUS DISEASE 2019 (COVID-19) IN IRAN
}

\author{
${ }^{1}$ Social Determinants of Health Research Center, School of Allied Medical Sciences, \\ Shahrekord University of Medical Sciences, Shahrekord, Iran \\ ${ }^{2}$ Department of Medical Physics and Radiology, School of allied medical sciences, \\ Shahrekord University of Medical Sciences, Shahrekord, Iran \\ ${ }^{3}$ Medical Faculty, Departaments of Psychiatry, Islamic Azad University, Khomen, Iran \\ ${ }^{4}$ Department of Internal Medicine, Shahrekord University of Medical Sciences, Shahrekord, Iran \\ ${ }^{5}$ Department of Environmental Health Engineering, School of Health, Shahrekord University of Medical \\ Sciences, Shahrekord, Iran \\ ${ }^{*}$ Corresponding Authors
}

\begin{abstract}
INTRODUCTION. The Coronavirus disease 2019 (COVID-19) outbreak is an increasing major global public health threat. Mortality rate varies across countries, therefore conducting studies on this disease in different countries is necessary, and will improve disease management worldwide.

OBJECTIVE. This study aimed to investigate the COVID-19 disease course characteristics in Iran.

METHODS. This is a retrospective study of 108 patients with confirmed COVID-19 from Feb 20 to June 20, 2020, at one Hospital in Iran. In summary, we obtained demographic data, clinical, laboratory, and chest CT findings of patients. The statistical analysis evaluated patients in two groups: recovered or died.

RESULT. In brief, cough $(70 / 108,64.8 \%)$ and fever $(69 / 108,63.9 \%)$ were the most common symptoms. CT scan findings of patients with COVID-19 showed that bilateral lung involvement was more common in deceased patients than recovered ones $(20 / 26,76.9 \%$ vs. 30/70, $42.8 \%, p=0.026)$. Laboratory findings of routine blood tests including Erythrocyte sedimentation rate (ESR), Fasting Blood Sugar (FBS), White Blood Cell (WBC), the number of platelets (PLTs) showed a significant difference between the two groups $(p<0.05)$. There were no significant differences in age and gender between the two groups.

CONCLUSION. In this study, we described the features of deceased and recovered patients with COVID-19. Our findings suggest that levels of FBS, ESR, WBC, and PLTs, also patterns of lung involvement, existence of underlying disease, respiratory rate, and oxygen saturation can be predictors of mortality risk. Further studies are proposed to investigate these characteristics in different populations.
\end{abstract}

Keywords: COVID-19, mortality, clinical features, demographics, chest CT, laboratory

\section{INTRODUCTION}

The novel human coronavirus disease 2019 (COVID-19) was first reported in the Chinese city of Wuhan in December 2019 (1) and has spread to many countries in the world, including Iran.

According to the latest statistical data and information on COVID-19 in Iran (the Islamic Republic of), from 3 January 2020 to 30 September 2021, there have been 5,572,962 confirmed COVID-19 cases with 120,160 deaths, reported to WHO (https:// www.who.int/data/gho/data/countries).

Remote work, confining people to their homes, closure of schools and universities, and implementation of virtual education, restrictions on travels are among the measures taken to control and prevent the spread of the virus. Nevertheless, the disease has spread widely. COVID-19 now appears to spread from person to person through the same mechanisms as cold viruses such as influenza. The most common symptoms of

(C) National Institute of Public Health NIH - National Research Institute / Narodowy Instytut Zdrowia Publicznego PZH - Państwowy Instytut Badawczy 
patients with this disease are fever, dyspnea, fatigue, dry cough, and myalgia (2). Due to advances in COVID-19 vaccines in pharmaceutical companies and international research groups around the world, COVID-19 features are better known. A combination of these can be very effective in ending the current and future infections of COVID-19 (3).

Identifying the demographics, laboratory, imaging, and clinical features of this disease will help to make a realistic evaluation and thus control the epidemic. For this reason, researching in this area will help to explore care and prevention approaches. Assessment of patient's features with COVID-19 has been previously reported, however, due to the complexity of the disease and increasing the number of patients and importantly, reported significant differences in the clinical and demographic characteristics of COVID-19 patients in different regions of the world (4), further studies are needed. Therefore, to investigate these characteristics in Iran, in this study, we evaluated the demographics, laboratory, imaging, epidemiology, clinical features of patients with COVID-19.

\section{MATERIAL AND METHODS}

For this retrospective study, we have obtained important parameters including the demographic data, clinical, laboratory and chest CT (computed tomography) findings of 108 hospitalized patients from patients' medical records from Feb 20 to June 20, 2020, at Hajar Hospital of Shahrekord city (a city in Iran). COVID-19 infection of all patients was confirmed by the RT-PCR test. Therefore, the inclusion criteria were: hospitalized patients who had a positive RT-PCR test. The final status of patients (recovered or deceased) recorded in their medical records was the criterion for classification into two groups. The study was approved by Shahrekord University of medical sciences Ethics Committee (Code No. IR.SKUMS.REC.1399.001) and the data was reviewed by a trained team of physicians. We recorded data on symptoms and vital signs and the medical history of COVID-19 patients. We then collected the laboratory results and chest CT findings of the patients. All patients underwent chest CT examinations and all imaging features were reviewed and evaluated by two experienced radiologists.

\section{Statistical analysis}

Categorical variables were described as counts and percentages and quantitative variables were described using mean and range values. The chi-square test and t-test (independent sample t-tests) were used for the difference between the categorical and quantitative variables with the number of recovered and deceased from COVID-19. P-values less than 0.05 were considered statistically significant and all statistical analyses were performed using SPSS 24.0 software package (SPSS Inc., Chicago, IL).

\section{RESULTS}

- Baseline characteristics of the study group:

The Demographics and clinical characteristics of these 108 patients are summarized in Table 1; the mean age of patients was 51.8 years and $47.2 \%$

Table 1. Demographics and clinical characteristics of patients hospitalized with COVID-19

\begin{tabular}{|c|c|}
\hline Variable & $\begin{array}{l}\text { All patients } \\
(\mathrm{n}=108)\end{array}$ \\
\hline Age (years) & $51.8(1-87)$ \\
\hline \multicolumn{2}{|l|}{ Gender : } \\
\hline Male & $51 / 108(47.2 \%)$ \\
\hline Female & $57 / 108(52.8 \%)$ \\
\hline \multicolumn{2}{|l|}{ Marital status: } \\
\hline Single & $12 / 108(11.1 \%)$ \\
\hline Married & $91 / 108(84.2 \%)$ \\
\hline Divorced & $1 / 108(.9 \%)$ \\
\hline Widowed & $4 / 108(3.7 \%)$ \\
\hline Condition: recovery / Death & $\begin{array}{c}82(75.9 \%) / \\
26(24.1 \%) \\
\end{array}$ \\
\hline Comorbidities: Yes/No & $\begin{array}{c}55(50.9 \%) / \\
53(49.1 \%)\end{array}$ \\
\hline Hypertension & $13 / 55(23.6 \%)$ \\
\hline Diabetes & $13 / 55(23.6 \%)$ \\
\hline Congestive heart failure & $8 / 55(14.5 \%)$ \\
\hline COPD & $6 / 55(10.9 \%)$ \\
\hline Chronic kidney disease & $5 / 55(9 \%)$ \\
\hline Organ transplants & $2 / 55(3.6 \%)$ \\
\hline Chemotherapy & $1 / 55(1.8 \%)$ \\
\hline Other diseases & $7 / 55(12.7 \%)$ \\
\hline Temperature $\left({ }^{\circ} \mathrm{C}\right)$ & $37.9^{\circ} \mathrm{C}(36-40)$ \\
\hline Respiratory rate (RR) frequency/min & $19(12-28)$ \\
\hline Oxygen saturation \% & $84.5(58-98)$ \\
\hline \multicolumn{2}{|l|}{ Symptoms: } \\
\hline Cough & $70 / 108(64.8 \%)$ \\
\hline Fever $\left(>38^{\circ} \mathrm{C}\right)$ & $69 / 108(63.9 \%)$ \\
\hline Dyspnea & $64 / 108(59.3 \%)$ \\
\hline Myalgia & $53 / 108(49.1 \%)$ \\
\hline Fatigue & $48 / 108(44.4 \%)$ \\
\hline Headache & $31 / 108(28.7 \%)$ \\
\hline Sore throat & $27 / 108(25 \%)$ \\
\hline Anosmia & $21 / 108(19.4 \%)$ \\
\hline Nausea/Vomiting & $17 / 108(15.7 \%)$ \\
\hline Diarrhea & $16 / 108(14.8 \%)$ \\
\hline Dysgeusia & $13 / 108(12 \%)$ \\
\hline
\end{tabular}

COPD: Chronic Obstructive Pulmonary Disease 
were male. The symptoms at the onset of illness were: cough $(70 / 108,64.8 \%)$, fever $(69 / 108,63.9 \%)$, dyspnea $(64 / 108,59.3 \%)$, myalgia $(53 / 108,49.1 \%)$, fatigue $(48 / 108,44.4 \%)$, headache $(31 / 108,28.7 \%)$, sore throat $(27 / 108,25 \%)$, anosmia $(21 / 108,19.4 \%)$, nausea $(17 / 108,15.7 \%)$, diarrhea $(16 / 108,14.8 \%)$ and dysgeusia (13/108, 12\%). Clinical examination revealed a temperature of $38.5^{\circ} \mathrm{C}$, a respiratory rate of 19 breaths per minute, and oxygen saturation $84.5 \%$. 55 patients with COVID-19 disease had comorbidities, such as hypertension (13/55( 23.6\%)), diabetes (13/55, 23.6\%), COPD $(6 / 55,10.9 \%)$, chronic kidney disease $(5 / 55,9 \%)$, congestive heart failure $(8 / 55,14.5 \%)$, cancer $(1 / 55,1.8 \%)$, organ transplants $(2 / 55,3.6 \%)$, or other diseases $(7 / 55,12.7 \%)$. Of the 108 patients, 82 recovered and 26 died.

- Laboratory and radiologic results:

Laboratory findings of routine blood tests such as levels of electrolytes like sodium, calcium, phosphorus, and potassium, white and red blood cell counts (WBC and $\mathrm{RBC}$ ), common liver function tests (included aspartate aminotransferase (AST), alanine aminotransferase (ALT) and alkaline phosphatase (ALP)), and other blood biochemistry are shown in Table 2.

Figure 1 shows the chest CT of a 58-years old female patient with confirmed COVID-19. The chest CT finding including ground-glass opacity (GGO), consolidation, and mixed GGO and consolidation were evaluated. 12/108 (11.1\%) patients showed normal chest CT. Out of 96 patients, 24/96 (22.2\%) showed the presence of GGO, 13/96 (12\%) patients showed the presence of consolidation, and 59/96 (54.6\%) showed

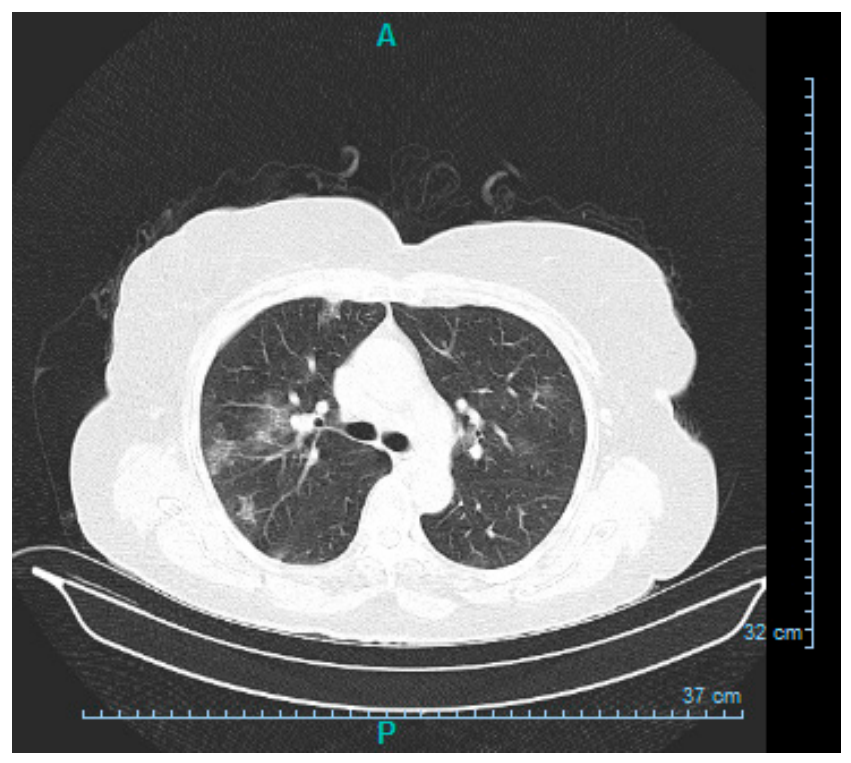

Figure 1. Chest CT of a female patient 58 years old with confirmed COVID-19 shows bilateral lung involvement.
Table 2. Laboratory findings of patients hospitalized with COVID-19

\begin{tabular}{|l|c|c|}
\hline \multicolumn{1}{|c|}{ Laboratory tests } & Units & $\begin{array}{c}\text { All patients } \\
\text { (n=108) } \\
\text { Mean (Range) }\end{array}$ \\
\hline Blood urea nitrogen (BUN) & $\mathrm{mg} / \mathrm{dL}$ & $30(3-90)$ \\
\hline Creatinine & $\mathrm{mg} / \mathrm{dL}$ & $1.22(.5-5.8)$ \\
\hline $\begin{array}{l}\text { Erythrocyte sedimentation } \\
\text { rate (ESR) }\end{array}$ & $\mathrm{mm} / \mathrm{hr}$ & $29(8-93)$ \\
\hline $\begin{array}{l}\text { Aspartate aminotransferase } \\
\text { (AST) }\end{array}$ & $\mathrm{U} / \mathrm{L}$ & $43.4(10-132)$ \\
\hline $\begin{array}{l}\text { Alanine aminotransferase } \\
\text { (ALT) }\end{array}$ & $\mathrm{U} / \mathrm{L}$ & $45(9-400)$ \\
\hline $\begin{array}{l}\text { Alkaline } \\
\text { phosphatase (ALP) }\end{array}$ & $\mathrm{U} / \mathrm{L}$ & $123.8(13.6-360)$ \\
\hline Sodium & $\mathrm{mmol} / 1$ & $136.5(129-150)$ \\
\hline Potassium & $\mathrm{mmol} / 1$ & $3.9(3.2-5.3)$ \\
\hline Phosphorus & $\mathrm{mmol} / 1$ & $3.4(1.2-5.3)$ \\
\hline Fasting Blood Sugar (FBS) & $\mathrm{mg} / \mathrm{dL}$ & $128.1(50-311)$ \\
\hline Hemoglobin & $\mathrm{g} / \mathrm{dL}$ & $12.8(3.1-17.2)$ \\
\hline Hematocrit & $\%$ & $38.6(24.7-53.6)$ \\
\hline White Blood Cell (WBC) & $\times 10^{3} / \mathrm{uL}$ & $8.6(1-31.3)$ \\
\hline Red Blood Cell (RBC) & $\times 10^{6} / \mathrm{uL}$ & $4.16(2.5-8)$ \\
\hline Prothrombin time (PT) & $\mathrm{sec}$ & $13(11-19)$ \\
\hline $\begin{array}{l}\text { Partial thromboplastin time } \\
\text { (PTT) }\end{array}$ & $\mathrm{sec}$ & $31.7(19-120)$ \\
\hline $\begin{array}{l}\text { International normalized } \\
\text { ratio (INR) }\end{array}$ & $\times 10^{3} / \mathrm{uL}$ & $155.4(10-400)$ \\
\hline Platelet count (PLT) & & $1.08(.9-2)$ \\
\hline
\end{tabular}

Table 3. Chest CT scan findings of patients hospitalized with COVID-19

\begin{tabular}{|l|c|}
\hline \multicolumn{1}{|c|}{ Findings } & patients \\
\hline GGOs and consolidation: & \\
\hline $\begin{array}{l}\text { Absence of both GGOs and } \\
\text { consolidation }\end{array}$ & $12 / 108(11.1 \%)$ \\
\hline $\begin{array}{l}\text { Presence of GGOs without } \\
\text { consolidation }\end{array}$ & $24 / 108(22.2 \%)$ \\
\hline $\begin{array}{l}\text { Presence of GGOs with } \\
\text { consolidation }\end{array}$ & $59 / 108(54.6 \%)$ \\
\hline $\begin{array}{l}\text { Presence of consolidation without } \\
\text { GGOs }\end{array}$ & $13 / 108(12 \%)$ \\
\hline $\begin{array}{l}\text { lung disease Unilateral / } \\
\text { Bilateral }\end{array}$ & $46(47.9 \%) / 5$ \\
\hline Frequency of lobe involvement: & $0(52.1 \%)$ \\
\hline Right upper lobe & $26 / 96(27 \%)$ \\
\hline Right middle lobe & $21 / 96(19.4 \%)$ \\
\hline Right lower lobe & $30 / 96(31.2 \%)$ \\
\hline Left upper lobe & $26 / 96(27 \%)$ \\
\hline Left lower lobe & $38 / 96(39.5 \%)$ \\
\hline
\end{tabular}

GGOs: Ground-Glass Opacities 
the mix of GGO and consolidation. The CT scan data is summarized in Table 3.

- Findings of recovery and death:

Patients with improved clinical picture compared to deceased patients had significantly different Vital Signs including respiratory rate $(p<0.05)$. The levels of the laboratory tests such as White blood cell and Platelet cell count ESR, AST, ALT, ALP, FBS, and Calcium were significantly different between the two groups $(p<0.05)$. Also, among the symptoms of the disease, fever, dyspnea, myalgia, anosmia, nausea, and dysgeusia showed a significant difference between the two groups $(\mathrm{p}<0.05)$ (Table 4$)$.

Table 4 . The relationship between study variables with recovery and death $p<0.05$ was considered statistically significant and bold font indicates statistical significance.

\begin{tabular}{|c|c|c|c|}
\hline Variable & $\begin{array}{c}\text { Recovery } \\
n=82\end{array}$ & $\begin{array}{c}\begin{array}{c}\text { Death } \\
n=26\end{array} \\
\end{array}$ & p-value \\
\hline Age (years) & 50.39 & 50.36 & .99 \\
\hline \multicolumn{4}{|l|}{ Gender : } \\
\hline Male & $40 / 82(48 \%)$ & $11 / 26(42 \%)$ & \multirow{2}{*}{.63} \\
\hline Female & $42 / 82(52 \%)$ & $15 / 26(58 \%)$ & \\
\hline Comorbidities: Yes/No & $34(41 \%) / 48(59 \%$ & $21(80 \%) / 5(20 \%)$ & $<.001$ \\
\hline Respiratory rate (RR) frequency/min & 25.1 & 16.8 & .03 \\
\hline Oxygen saturation $\%$ & 87.9 & 80.4 & .008 \\
\hline \multicolumn{4}{|l|}{ Symptoms: } \\
\hline Cough & $56 / 82(68 \%)$ & $14 / 26(53 \%)$ & .29 \\
\hline Fever $\left(>38^{\circ} \mathrm{C}\right)$ & $51 / 82(62 \%)$ & $18 / 26(69 \%)$ & .03 \\
\hline Dyspnea & $47 / 82(57 \%)$ & $17 / 26(65 \%)$ & .03 \\
\hline Myalgia & $40 / 82(48 \%)$ & $13 / 26(50 \%)$ & .03 \\
\hline Fatigue & $36 / 82(44 \%)$ & $12 / 26(46 \%)$ & .07 \\
\hline Headache & $26 / 82(31 \%)$ & $5 / 26(19 \%)$ & .69 \\
\hline Sore throat & $24 / 82(29 \%)$ & $3 / 26(11 \%)$ & .61 \\
\hline Anosmia & $17 / 82(20 \%)$ & $4 / 26(15 \%)$ & .02 \\
\hline Diarrhea & $12 / 82(14 \%)$ & $4 / 26(15 \%)$ & .32 \\
\hline Nausea/vomiting & $9 / 82(11 \%)$ & $8 / 26(30 \%)$ & .003 \\
\hline Dysgeusia & $9 / 82(11 \%)$ & $4 / 26(15 \%)$ & .003 \\
\hline Bilateral lung disease & $30 / 70(42.8 \%)$ & $20 / 26(76.9 \%)$ & .026 \\
\hline Unilateral lung disease & $40 / 70(57.1 \%)$ & $6 / 26(23 \%)$ & .041 \\
\hline Blood urea nitrogen (BUN) & 32.3 & 31 & .52 \\
\hline Creatinine & .98 & 1.2 & .59 \\
\hline Erythrocyte sedimentation rate (ESR) & 31.4 & 20.9 & .04 \\
\hline Aspartate aminotransferase (AST) & 57.3 & 47.7 & .82 \\
\hline Alanine aminotransferase (ALT) & 43.3 & 65.2 & .37 \\
\hline Alkaline phosphatase (ALP) & 97.3 & 120.7 & .35 \\
\hline Sodium & 135.9 & 137.2 & .76 \\
\hline Potassium & 4 & 3.9 & .38 \\
\hline Phosphorus & 2.7 & 3 & .51 \\
\hline Fasting Blood Sugar (FBS) & 117.4 & 143.9 & .03 \\
\hline Hemoglobin & 12.9 & 12.5 & .55 \\
\hline Hematocrit & 38.3 & 38.9 & .72 \\
\hline White Blood Cell (WBC) & 7417 & 4719 & .02 \\
\hline Red Blood Cell (RBC) & 4.1 & 4.3 & .052 \\
\hline Prothrombin time $(\mathrm{PT})$ & 13.2 & 13.2 & .96 \\
\hline Partial thromboplastin time (PTT) & 32 & 31.6 & .92 \\
\hline International normalized ratio (INR) & 1 & 1.1 & .61 \\
\hline Platelet count (PLT) & 155 & 103 & .04 \\
\hline
\end{tabular}




\section{DISCUSSION}

Coronavirus disease (COVID-19) is a human infectious disease caused by a new virus that belongs to the family of coronaviruses and has caused a large number of deaths around the world (5). In terms of mortality in this study, the mortality rate of patients with underlying diseases $(21 / 26,80 \%)$ is significantly higher than that of patients without underlying diseases $(5 / 26,20 \%)(p<.001)$. According to previous findings, COVID-19 patients with the underlying disease are more vulnerable and have a higher risk of death that our study confirms these findings $(6,7)$. The most common comorbidity is hypertension and diabetes mellitus (both 13/55, 23.6 \%). This is followed by congestive heart failure $(8 / 55,14.5 \%)$ and other diseases.

Although in many studies mortality in COVID-19 was higher in men and the elderly $(5,8-10)$, in this study, no significant difference in terms of gender and age was observed between the recovered and deceased patients, However, this can be affected by the small sample size (11). Among the people who died, fever $(18 / 26,69 \%)$, dyspnea $(17 / 26,65 \%)$, and cough $(14 / 26$, $53 \%)$ and in recovered patients, cough $(56 / 82,68 \%)$ fever $(51 / 82,62 \%)$, and dyspnea $(47 / 82,57 \%)$ were the most common symptoms, respectively. Previous studies reported abnormalities in routine laboratory blood tests of COVID-19 patients. A low white blood cell (WBC) count which indicates a weakened immune system can be caused by a COVID-19 infection (12). In our study, WBC was significantly different between the two groups and was decreased in the dead group compared to the recovered patient group $(\mathrm{p}=<.05)$. Therefore, the low WBC count might be related to patients death. However, this finding is not consistent with the results of the study of Chen, Fuyang et al. - their findings show that the WBC count of the nonsurvivor group were significantly higher than of the survivor group (13).

Also, the results collected in the study of Feng, Xudong, et al. show that the number of WBC in severe COVID-19 patients is higher than in less severe patients and also the increase in WBC is strongly associated with disease exacerbation in COVID-19 patients. It can be noted that these results are not consistent with our findings and it is suggested that the value of WBC be closely monitored in future studies (14).

Hyperglycemia reported in COVID-19 patients may have been due to diabetes or non-diabetic.

One of the possible causes is the use of steroids that is common in COVID-19 and the treatment may also affect the patient's glycemia (15). Previous studies showed that high fasting blood sugar (FBS) in these patients is a strong predictor of death $(12,16,17)$. Stress can be one of the factors that cause high blood sugar in COVID-19 patients without diabetes (18). Overall measurement of FBS levels may lead to prognosis assessment and patient stress management and improve COVID-19 treatment outcomes. Therefore, measuring the FBS level should be recommended for all COVID-19 patients, even if they do not have diabetes. Further studies are needed to evaluate the findings of COVID-19 disease in diabetic and nondiabetic patients.

CT scan findings of patients with COVID-19 showed that consolidation, ground-glass, or mixed is more common in the right and left lower lobe than other lobes. Bilateral lung involvement was more common in patients who died than recovered patients $(20 / 26$, $76.9 \%$ vs. $30 / 70,42.8 \%, p=0.026$ ), and unilateral lung involvement was more common in recovered patients compared with deceased patients, (40/70, $57.1 \%$ vs. $6 / 26,23.1 \%, p=0.041)$. In a retrospective cohort study, hypoxemia $(\mathrm{SpO} 2 \leq 90 \%$ despite oxygen supplementation) was associated with mortality (19). In the present study, oxygen saturation showed a significant difference between the group of dead and recovered patients. Vital signs such as respiratory rate also showed significant differences between the two groups $(\mathrm{p}=<.05)$.

Limitations. This study has several limitations. First, the sample size was relatively small. Second, the results of laboratory tests and CT scans were obtained at different times of the disease period of these patients, which can affect the results. Third, we collected information from patients admitted with COVID-19 in a hospital in Shahrekord, not all patients. Therefore, the results can only describe the clinical and epidemiological features of patients with COVID-19 in this hospital. Therefore, a more comprehensive study of all patients is required.

\section{CONCLUSION}

In this study, we described the features of dead and recovered COVID-19 patients. Based on these results, lung damage can occur in most COVID-19 patients. The imaging pattern of most patients in our study involved mixed GGO and consolidation with predominance in the left lower lung. Bilateral lung involvement was more common in patients who died than recovered patients which may be an imaging biomarker to predict death in these patients. Also, another parameter discussed was the high FBS in deceased patients which can increase the risk of mortality in patients with COVID-19. These features can lead to an assessment of disease severity and mortality risk in patients with COVID-19. As this virus is still considered a global health threat, additional research is needed. 
Ethical Approval: The study was approved by Shahrekord University of medical sciences Ethics Committee (Code No. IR.SKUMS.REC.1399.001).

Funding: This study was financially supported by a grant from the Vice Chancellor of Research of Mashhad University of Medical Sciences; grant number 5348 .

Conflicts of interest: The authors declare no conflict of interest, financial or otherwise.

Acknowledgments: We acknowledge the patients, the referring clinicians, and Hajar Hospital's medical records department.

\section{REFERENCES}

1. Liu YC, Kuo RL, Shih SR. COVID-19: The first documented coronavirus pandemic in history. Biomed J. 2020;43(4):328-333. doi: 10.1016/j. bj.2020.04.007

2. D'Adamo H, Yoshikawa T, Ouslander JG. Coronavirus disease 2019 in geriatrics and longterm care: the ABCDs of COVID-19. J Am Geriatr Soc 2020;68(5):912-7.

3. Excler JL, Saville M, Berkley S, Kim JH. Vaccine development for emerging infectious diseases. Nat Med 2021;27(4):591-600.

4. Wang R, Pan M, Zhang X, et al. Epidemiological and clinical features of 125 Hospitalized Patients with COVID-19 in Fuyang, Anhui, China. Int J Infect Dis. 2020;95:421-8.

5. Chen F, Sun W, Sun S, et al. Clinical characteristics and risk factors for mortality among inpatients with COVID-19 in Wuhan, China. Clin Transl Med 2020;10(2):e40. doi: 10.1002/ctm2.40

6. Vakili S, Savardashtaki A, Jamalnia S, Tabrizi R, et al. Laboratory Findings of COVID-19 Infection are Conflicting in Different Age Groups and Pregnant Women: A Literature Review. Arch Med Res. 2020;51(7):603-607. doi: 10.1016/j. arcmed.2020.06.007

7. Clark A, Jit M, Warren-Gash C, et al. Global, regional, and national estimates of the population at increased risk of severe COVID-19 due to underlying health conditions in 2020: a modelling study. Lancet Glob Health 2020;8(8):e1003-e17.

8. Bhandari S, Singh A, Sharma R, et al. Characteristics, Treatment Outcomes and Role of Hydroxychloroquine among 522 COVID-19 hospitalized patients in Jaipur City: An EpidemioClinical Study. J Assoc Physicians India. 2020;68(6):13-19.

9. Zhou F, Yu T, Du R, et al. Clinical course and risk factors for mortality of adult inpatients with
COVID-19 in Wuhan, China: a retrospective cohort study. Lancet. 2020;395(10229):1054-1062

10. Li J, Xu G, Yu H, et al. Clinical characteristics and outcomes of 74 patients with severe or critical COVID-19. Am J Med Sci. 2020;360(3):229-235.

11. Faber J, Fonseca LM. How sample size influences research outcomes. Dent Press J Orthod 2014;19(4):27-9.

12. Chen N, Zhou M, Dong X, et al. Epidemiological and clinical characteristics of 99 cases of 2019 novel coronavirus pneumonia in Wuhan, China: a descriptive study. Lancet 2020;395(10223):50713.

13. Chen F, Sun W, Sun S, et al. Clinical characteristics and risk factors for mortality among inpatients with COVID-19 in Wuhan, China. Clin Transl Med 2020;10(2):e40.

14. Feng X, Li S, Sun Q, et al. Immune-Inflammatory Parameters in COVID-19 Cases: A Systematic Review and Meta-Analysis. Front Med. 2020;7:301.

15. Saand AR, Flores M, Kewan T, et al. Does inpatient hyperglycemia predict a worse outcome in COVID-19 intensive care unit patients? J Diabetes 2021;13(3):253-260.

16. Lepper PM, Bals R, Jüni $\mathrm{P}$, et al. Blood glucose, diabetes and metabolic control in patients with community-acquired pneumonia. Diabetologia 2020: 63(11):2488-2490

17. Singh AK, Singh R. Hyperglycemia without diabetes and new-onset diabetes are both associated with poorer outcomes in COVID-19. Diabetes Res Clin Pract. 2020;167:108382.

18. Wang S, Ma P, Zhang S, et al. Fasting blood glucose at admission is an independent predictor for 28-day mortality in patients with COVID-19 without previous diagnosis of diabetes: a multicentre retrospective study. Diabetologia 2020;63(10):2102-2111.

19. Xie J, Covassin N, Fan Z, et al. Association Between Hypoxemia and Mortality in Patients With COVID-19. Mayo Clin Proc. 2020;95(6):11381147.

\section{Received: 25.07.2021}

Accepted for publication: 14.10.2021

\section{Address for correspondence:}

Prof. Ali Hasanpour Dehkordi

Social Determinants of Health Research Center

School of Allied Medical Sciences,

Shahrekord University of Medical Sciences,

Shahrekord, Iran

Tel: 989133830205

E-Mail: ali20121968@yahoo.com 